\title{
REACTIVE EXTRUSION OF POLYAMIDE 6 USING A NOVEL CHAIN
} EXTENDER

\author{
B. Tuna and H. Benkreira ${ }^{1}$ \\ School of Engineering, R\&KT Centre in Advanced Materials Engineering \\ University of Bradford, BD7 1DP, UK
}

\begin{abstract}
Polyamide 6 (PA6) is an important engineering thermoplastic, very widely used but prone to thermal degradation during extrusion at temperature not far from its melt temperature $\left(220^{\circ} \mathrm{C}\right)$. Typically, and as measured in this study, PA6 extruded at temperature of $300{ }^{\circ} \mathrm{C}$ shows a $40 \%$ decrease in tensile modulus compared to non-extruded PA6. To rebuild PA6 molecular weight, the easiest and cheapest method is to use an appropriate chain extender. Many chain extenders have been used in the past but they are essentially suited to nucleophile induced degradation, targeting split PA6 chains carboxyl $\mathrm{COOH}$ and amine $\mathrm{NH}_{2}$ end groups. What has been lacking are effective chain extenders for thermally only induced degradation, i.e. for the practical cases where the PA6 is thoroughly dried before extrusion. For such a case, the degradation reaction mechanism dictates that the solution is to develop chain extenders that target the split PA6 chains amide $\mathrm{CONH}_{2}$ groups not the carboxyl $\mathrm{COOH}$ and amine $\mathrm{NH}_{2}$ end groups. As amide groups strongly react with anhydride functionalities, we test the effectiveness of a novel chain extender, Joncryl ${ }^{\circledR}$ ADR 3400 , a styrene maleic anhydride copolymer with multiple, repeating anhydride functionality. Assessment of chain extension in this study is done as with previous work, using rheology, mechanical and thermal properties of PA6 extruded on its own and with the chain extender. The viscoelastic data conclusively show the efficacy of such chain extender with more than 10 fold changes in the comparative values of the extruded sample storage modulus $G^{\prime}$ and as much as an $85 \%$ increase in the tensile modulus.
\end{abstract}

Keywords: Polyamide 6, thermal degradation, extrusion, chain extender, rheology, thermal properties.

\section{INTRODUCTION}

Polyamide 6 (PA6) is one of the most important engineering thermoplastic polymers, the first ever commercially produced, way back in the 1930's [1]. It is moderately priced and with excellent mechanical properties and chemical resistance. PA6 has been mainly used in the textile industry as a substitute of natural fibres but has found increased application in the automotive industry (gears, bearings and fittings), packaging and in the manufacture of parts and products which must be tough, impact resistant and abrasion resilient such as power tools and electronic housings and the large variety of threads, ropes and filaments [2-3]. PA6 has found even greater application following the breakthrough by researchers at Toyota who in the 1980s compounded it with nano-clays to pave the way for the development of polymer nanocomposites [4]. PA6 nanocomposites are now used to fabricate automotive timing belts,

\footnotetext{
${ }^{1}$ Corresponding author e-mail address: H.Benkreira@bradford.ac.uk
} 
engine covers, doors, seat backs, fuel lines and other car components as well as strong drink bottles and packaging.

Like all thermoplastics, PA6 is heated before being shaped into a final product, usually in an extruder or an injection moulding machine where the melted polymer is intensely sheared at temperatures higher than its melt temperature $\left(220{ }^{\circ} \mathrm{C}\right)$ for several minutes when processed at industrial scale [5]. At extrusion temperatures above $300{ }^{\circ} \mathrm{C}$, such exposure to heat and shear causes PA6 degradation, a chemical reaction where one of two chain scissions can occur: (i) a thermal only breaking of the chain linking the amide $\mathrm{CONH}_{2}$ and alkyl group $(\mathrm{CH} 2)_{5}$ or (ii) if water is present, the chain linking the carboxyl $(\mathrm{COOH})$ and amine $\left(\mathrm{NH}_{2}\right)$ groups in the recurring amide group $(\mathrm{CO}-\mathrm{NH})$ is hydrolysed [6-8]. These degradation reaction mechanisms are shown in Fig. 1. As a result, the molecular weight of the polymer chain so attacked drops and the mechanical properties are weakened [9].

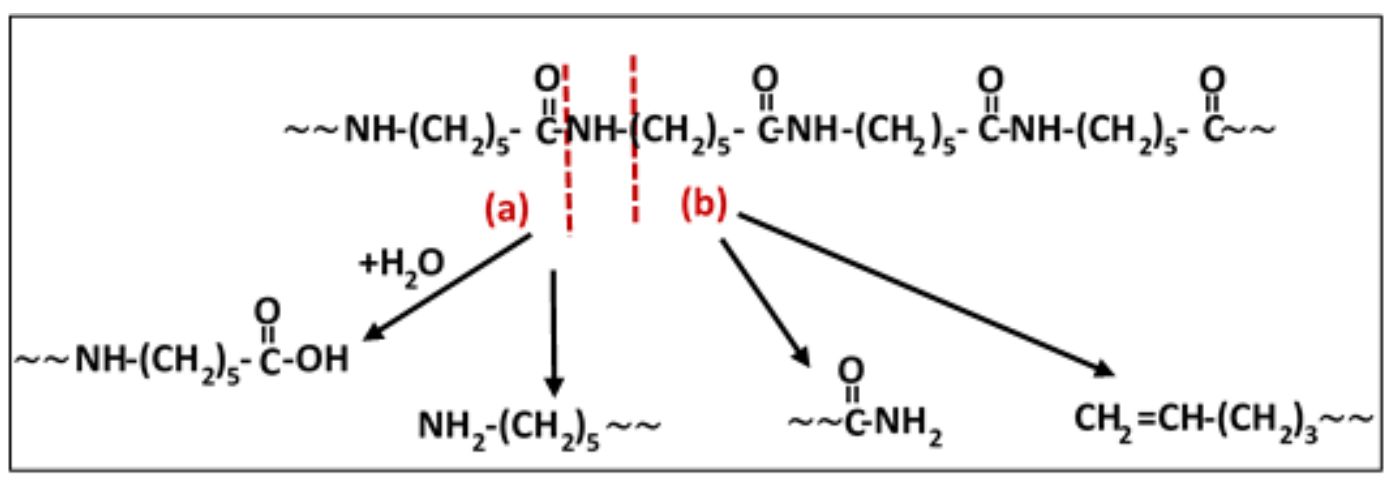

Fig. 1: Nucleophile and thermal degradation reactions of PA6

This explains why strict precautions are exercised during the extrusion of PA6 to ensure no exposure to moisture or excessively high temperatures. Whereas the removal of moisture is in principle not problematic, the reduction of temperature poses processing issues: low temperatures, close to the melting point, make for a very viscous flow in the extruder and moulding, reduce production and increase cost of manufactured products. When processing recycled PA6, a necessity in a sustainable economy, the situation is aggravated as repeated extrusion requires lowering the temperature even further. Clearly, in order to facilitate flow for both pristine and recycled PA6 it would be desirable to extrude at temperatures sufficiently above the polymer melting point if the reduction of molecular weight could be built-back.

The main approach used to increase the molecular weight of pristine or recycled PA6 is solid-state polymerisation (SSP), a well-established technique, going back to the 1930s [10], in which the polymer particles are heated prior to extrusion at a temperature below the melting point in an oxygen, moisture free atmosphere using either vacuum or purging with an inert gas to drive off the reactions by-products. This is an added step in processing, making the overall extrusion operation costly. A cheaper alternative is the use of chain extenders, chemicals that are simply added to the polymer being extruded. These react with the potentially degrading (pristine) or degraded (recycled) PA6 and rebuild its structure. This method has received in recent years much attention [11-21], being researched for application for a variety of polymers, polyethylene terephthalate (PET), polybutylene terephthalate (PBT), polycarbonate (PC), polylactic acid (PLA), polyhydroxyalkanoate (PHA) as well as for PA6 as we shall see below. The principle behind this method is simple: the chain extender is composed of groups (functionalities) that react during melt extrusion with the end groups 
of the broken chains of the polymer and in doing form bridges that recouple the polymer chains. This results with a rebuilding of the molecular weight. With the high reactivity of chain extenders and extrusion temperatures, there is however the possibility of side reactions so the chain extenders have to be formulated carefully.

With PA6, the formulation strategy of an appropriate chain extender will depend on whether the degradation mechanism that is taking place is driven by water moisture or high temperature. Accordingly, and following Fig.1, for moisture induced degradation, the approach in the formulation will be to develop chain extension molecules that will react at very small dosages $(1 \mathrm{wt} . \%)$ with the split PA6 chains carboxyl $\mathrm{COOH}$ and amine $\mathrm{NH}_{2}$ end groups and reconnect them whereas in the case of no moisture, it is the amide $\mathrm{CONH}_{2}$ groups that must be the reconnecting links. Thus, along this strategy, compounds such as carbonylbiscaprolactam (CBC), phenylene bisoxazoline (PBO) and isophthaloyl biscaprolactamate (IBC) have been developed as effective chain extenders but only as an answer to the moisture induced degradation. Table 1 gives the molecular structure of these compounds, now extensively used. Loontjens et al. [22] for example used PBO and IBC to chain extend PA6 during extrusion and observed that the moisture chain extension anticipated had indeed occurred with the PBO reacting with the carboxylic end groups and the IBC with the amine end groups. Interestingly, they observed (i) the effect to be more pronounced when the PBO and IBC were added simultaneously rather than separately and (ii) a drawback in IBC in that it has a relatively low reaction rate and in order to achieve the desired chain extension would require long reaction times which may lead to degradation. Lu et al. [23] on the other hand focussed on the carboxylic end group only using the chain extender PBO and found a relatively lower increase in the viscosity of the reacting mix suggesting that targeting the carboxylic end group is not the best approach as the reconstructed polyamide will contain an excess of amine end groups which adversely affects the thermal oxidative stability as remarked by Loontjens and Plum [24]. The correct strategy Loontjens and Plum [24] proposed is to target the amine end groups and to that effect they used CBC. The success of this approach was confirmed recently by Buccella et al. [25] who observed that an extrusion residence time of $3 \mathrm{~min}$ was enough to achieve chain extension. Also, end group analysis showed that the $\mathrm{CBC}$ had reacted only the amine end groups. Table 1 shows the structure of these $\mathrm{PBO}, \mathrm{IBC}$ and $\mathrm{CBC}$ all of which have at most two functionalities capable of reacting with moisture induced degraded PA6 with end $\mathrm{COOH}$ and $\mathrm{NH}_{2}$.

What has been lacking is a solution to the thermal only degradation of PA6, i.e. finding chain extension molecules able to react with the amide group $\mathrm{CONH}_{2}$. As multifunctionality, several groups able to react in this case with $\mathrm{CONH}_{2}$, is key, a polymer with one very effective functionality repeated is the ideal solution sought. As the anhydride functionality is found to be strongly reactive with amide group, how about the performance of chain extenders with multi-anhydride functionalities? This paper tests precisely this hypothesis using a new chain extender, Joncryl ${ }^{\circledR}$ ADR 3400, a styrene maleic anhydride copolymer with repeated anhydride groups (see structure in Table 1). As with previous studies, the method of assessing chain extension will be via rheological measurements supplemented here with mechanical and thermal properties measurements of the extrudates. Rheology and mechanical properties provide direct link with structure and the extent to which they will change will give a good indication of the efficacy of the chain extension achieved. As noted early and evident from stoichiometry, the required amount of chain extender will be very small, typical of order $1 \mathrm{wt} . \%$. This poses the problem of ensuring correct feeding and thorough mixing of such tiny amount into the PA6. 
Table 1: Joncryl ${ }^{\circledR}$ ADR 4300 and chain extenders used in previous of studies

\begin{tabular}{|c|c|c|c|}
\hline Chain extender & $\begin{array}{c}\text { Joncryl }{ }^{\circledR} \mathrm{ADR} 3400 \\
\text { group or combinations of them; } \mathrm{R} 7 \text { is } \\
\text { an alkyl group and } \mathrm{x}, \mathrm{y} \text { and } \mathrm{z} \text { are } \\
\text { styrene, acrylic and maleic ahydride } \\
\text { groups respectively, between } 1 \text { and } 20 .\end{array}$ \\
$\begin{array}{c}\text { Phenylene bisoxazoline (PBO) } \\
\text { Isophthaloyl biscaprolactamate (IBC) }\end{array}$
\end{tabular}

\section{EXPERIMENTAL METHOD}

\subsection{Materials}

As explained, the chain extender in this study, Joncryl ${ }^{\circledR}$ ADR 3400 is a multifunctional chain extender with a high anhydride functionality, reacting very rapidly with $\mathrm{CONH}_{2}$ chain end groups and requiring very small dosage. According to the manufacturer specifications, Joncryl ${ }^{\circledR}$ ADR 3400 is thermally stable up to $320{ }^{\circ} \mathrm{C}$ and at dosage of only 0.5-1.0 wt.\%, a 99\% reaction completion is achieved in $45 \mathrm{~s}$ at $280{ }^{\circ} \mathrm{C}$ (BASF 2012). These specifications guided the dosage, extrusion temperatures and screw speeds to be tested. It has density of $600 \mathrm{~kg} / \mathrm{m}^{3}$ at $25{ }^{\circ} \mathrm{C}$, molecular weight of $10,000 \mathrm{~g} / \mathrm{mol}$ and glass transition temperature of $133{ }^{\circ} \mathrm{C}$. The PA6 polymer was grade Akulon F-136 from DSM with a melt temperature given in the specifications as $235^{\circ} \mathrm{C}$ and a nominal melt viscosity of $2250 \mathrm{~Pa}$.s at $260{ }^{\circ} \mathrm{C}$. In what follows Joncryl ${ }^{\circledR}$ ADR 3400 is also referred to as "Joncryl". In the tabulated results and figures it is abbreviated to "JC" and the word extruded is shortened to "ext".

\subsection{Extrusion}

Compounding of the PA6 with the chain extender was carried using an intermeshing co-rotating twin extruder. Although of small output $(4.5 \mathrm{~kg} / \mathrm{hr}$ at $200 \mathrm{rpm}$ screw speed), the extruder is representative of equipment used in large scale operation as it enabled the changing of the main operating parameters, screw speed and temperature. The extruder was a Baker Perkins APV MP19 TC28 that it is it has two $19 \mathrm{~mm}$ diameter screws with a length to 
diameter ratio of 28 forming essentially five independently temperature controlled zones: a feed zone, a first mixing zone, a compression zone, a second mixing zone and finally a conveying zone toward the exit die. The mixing zones were fitted with paddles positioned at $90^{\circ}, 12$ paddles in the first mixing zone and 8 paddles in the second mixing zone, these to ensure good dispersive mixing of the chain extender into the polymer melt.

With regard to feeding, two calibrated feeders were used to feed the polymer pellets and chain extender granules simultaneously at the required rates directly to the compounding screws. Prior to compounding, the polymer and chain extenders were dried in a vacuum oven at $80{ }^{\circ} \mathrm{C}$ for 12 hours.

As for the actual operation, the extruded compound exited the die as a strand about 3 $\mathrm{mm}$ in diameter pulled through a $1.5 \mathrm{~m}$ long cold water bath into a pelletizer. After several trials, temperature in the range $260-300{ }^{\circ} \mathrm{C}$ and screw speeds in the range $100-200 \mathrm{rpm}$ were found to produce suitable extrusion. Processing below $260{ }^{\circ} \mathrm{C}$ led to over-torque on the drive motor and above $300{ }^{\circ} \mathrm{C}$, the polymer viscosity was too low. At set temperature and screw speed, extrusion output was measured by collecting a length of strand over a five-minute period and weighting it. The procedure was repeated at least five times to obtain an accurate mean flow rate. The extrusion residence time was measured using a carbon black tracer. We report here seven runs covering a range of chain extender loadings, extrusion temperatures and screw speeds as shown in Table 2.

Table 2: Range of experimental conditions tested

\begin{tabular}{|c|c|c|c|c|c|c|c|c|c|c|}
\hline \multirow{3}{*}{ Run } & \multirow{3}{*}{\begin{tabular}{|c|} 
PA6 \\
(wt.\%)
\end{tabular}} & \multirow{3}{*}{$\begin{array}{c}\text { JC } \\
\text { (wt.\%) }\end{array}$} & \multirow{3}{*}{$\begin{array}{l}\begin{array}{l}\text { Screw } \\
\text { speed }\end{array} \\
\text { (rpm) }\end{array}$} & \multirow{3}{*}{$\begin{array}{c}\begin{array}{c}\text { Residence } \\
\text { time }\end{array} \\
(s)\end{array}$} & \multirow{3}{*}{$\begin{array}{c}\begin{array}{c}\text { Output } \\
\text { capacity }\end{array} \\
(\mathrm{kg} / \mathrm{hr})\end{array}$} & \multicolumn{5}{|c|}{ Zone temperature $\left({ }^{\circ} \mathrm{C}\right)$} \\
\hline & & & & & & 1 & 2 & 3 & 4 & 5 \\
\hline & & & & & & \multicolumn{4}{|c|}{ Feed } & Die \\
\hline 1 & 100 & 0 & 100 & 62 & 3000 & 230 & 260 & 260 & 260 & 260 \\
\hline 2 & 100 & 0 & 200 & 49 & 4500 & 230 & 260 & 260 & 260 & 260 \\
\hline 3 & 100 & 0 & 100 & 62 & 3000 & 230 & 300 & 300 & 300 & 300 \\
\hline 4 & 99 & 1 & 100 & 63 & 3000 & 230 & 260 & 260 & 260 & 260 \\
\hline 5 & 99 & 1 & 200 & 50 & 4500 & 230 & 260 & 260 & 260 & 260 \\
\hline 6 & 99 & 1 & 100 & 62 & 3000 & 230 & 300 & 300 & 300 & 300 \\
\hline 7 & 98.5 & 1.5 & 100 & 64 & 3000 & 230 & 260 & 260 & 260 & 260 \\
\hline
\end{tabular}

\subsection{Characterization of the Extrudates}

The characterization of the extrudates obtained, PA6 on its own and PA6 with the chain extender was carried out using rheological, mechanical, crystallization and degradation properties measurements.

Rheology: This was measured with a Bohlin CVO120 rheometer from Malvern Instruments using a parallel $25 \mathrm{~mm}$ diameter plates geometry with a $1 \mathrm{~mm}$ gap size at the pertinent extrusion temperatures. Time sweep tests were performed to determine the thermal stability of the samples over time. The tests were carried out at $1 \mathrm{~Hz}$ frequency over $1000 \mathrm{~s}$. Frequency sweep tests were conducted across a frequency range of 0.1 to $100 \mathrm{~Hz}$ at $0.1 \%$ strain, which was obtained from amplitude sweep tests to determine the linear viscoelastic region. These tests were carried out to establish the extent of structural change upon addition 
of the chain extender. The contribution of thermal degradation during frequency sweep tests was less than $5 \%$ and considered to be negligible. Three samples were tested for each measurement and the results were repeatable (0.2-5.7\% standard error). With each experiment, a new sample was used.

Mechanical Properties: These were measured under ambient conditions with a $20 \mathrm{kN}$ tensile machine Beta from Messphysik at a cross-head speed of $5 \mathrm{~mm} / \mathrm{min}$ with the strain measured on the dumbbell shaped testing specimens according to ISO 37_4 test standard (middle section $12 \mathrm{~mm}$ long x $2 \mathrm{~mm}$ wide $\times 0.80 \mathrm{~mm}$ thick) very accurately using a video extensometer. At least five samples were tested and average results with standard deviations were reported for each material. The specimens were obtained by first moulding samples at $240{ }^{\circ} \mathrm{C}$ in a hydraulic press (Moore Ltd, UK) under $300 \mathrm{MPa}$ for $2 \mathrm{~min}$. After cooling to 30 ${ }^{\circ} \mathrm{C}$, the moulded samples were cut into the dumbbell shapes using a Metaserv Instrument.

Thermal Properties: These included crystallization and thermal decomposition properties. Crystallization was measured with a Differential Scanning Calorimetry, Discovery DSC from TA Instruments. The samples, no more than $10 \mathrm{mg}$, and TA Instruments standard aluminum pans and lids were weighted carefully using a precision balance then encapsulated. Heatingcooling-heating cycles $\left(25{ }^{\circ} \mathrm{C} \rightarrow 260{ }^{\circ} \mathrm{C} \rightarrow 25{ }^{\circ} \mathrm{C} \rightarrow 260{ }^{\circ} \mathrm{C}\right)$ at a rate of $10{ }^{\circ} \mathrm{C} / \mathrm{min}$ under a nitrogen purge were performed on the samples to obtain the DSC thermosgrams from which the degree of crystallinity, glass transition, melt temperature and enthalpy of melting can be extracted. Degradation and thermal decomposition was assessed with a Discovery ThermoGravimetric Analyzer (TGA) from TA Instruments which measured mass change and the rate of mass change as a function of temperature, time and atmosphere. Here we used $10 \mathrm{mg}$ of sample in the temperature range from 25 to $600{ }^{\circ} \mathrm{C}$, with a heating rate of $10{ }^{\circ} \mathrm{C} / \mathrm{min}$ under nitrogen purge at a flow rate of $50 \mathrm{~mL} / \mathrm{min}$

\section{RESULTS AND DISCUSSION}

\subsection{Rheology}

Fig. 2 presents the results from the time sweep experiments in the form of complex viscosity $\eta^{*}$ changes at $1 \mathrm{~Hz}$ over a deformation period of $1000 \mathrm{~s}$. For a better comparison, the complex viscosity of the samples at 200, 400 and $800 \mathrm{~s}$ are given in Table 3 . Non extruded PA6 without chain extender shows a reduction of $\eta^{*}$ with time at the temperatures and screw speeds tested suggesting thermal degradation when the duration of the deformation imposed is excessive, say larger than 300s. Fig. 2 also displays the data for the PA6 compounded with the chain extender under the same conditions. The changes in the magnitude of $\eta^{*}$ are striking, nearly a four-fold increase. Moreover, whereas with the neat PA6, $\eta^{*}$ was observed to decrease with time, with the PA6 compounded with the chain extender, the reverse is observed. These results suggest that not only chain extension has occurred and is very significant, it continues to develop during the rheological tests. Similar observations regarding chain extension continuing during rheological testing were reported with other chain extenders by Ghanbari et al. [14] and Meng et al. [16]. Interestingly, comparing the data at $100 \mathrm{rpm}$ at $260{ }^{\circ} \mathrm{C}$ and $300{ }^{\circ} \mathrm{C}$ would suggest that there is a maximum temperature above which Joncryl chain extension effectiveness is reduced. Normally reactivity should increase with temperature (from $260{ }^{\circ} \mathrm{C}$ and $300{ }^{\circ} \mathrm{C}$ ) but here we see the reverse which is consistent with the manufacturer claim that at $320{ }^{\circ} \mathrm{C}$, Joncryl becomes thermally unstable. The data at $260{ }^{\circ} \mathrm{C}$ and screw speeds of $100 \mathrm{rpm}$ presented here provides an estimate of the extent of the chain extension reaction in the extruder about $85 \%$ when computed approximately from the relative increase of $\eta^{*}$, from 800 Pa.s (PA6 extruded with chain extender) to 3000 Pa.s, deemed to be the value of $\eta^{*}$ of the chain extended PA6 before 
1 the start of the rheological testing, compared to an increase from 800 to 3400 Pa.s, the $\eta^{*}$

2 value reached after 1000 s, deemed to be $100 \%$ completion time.

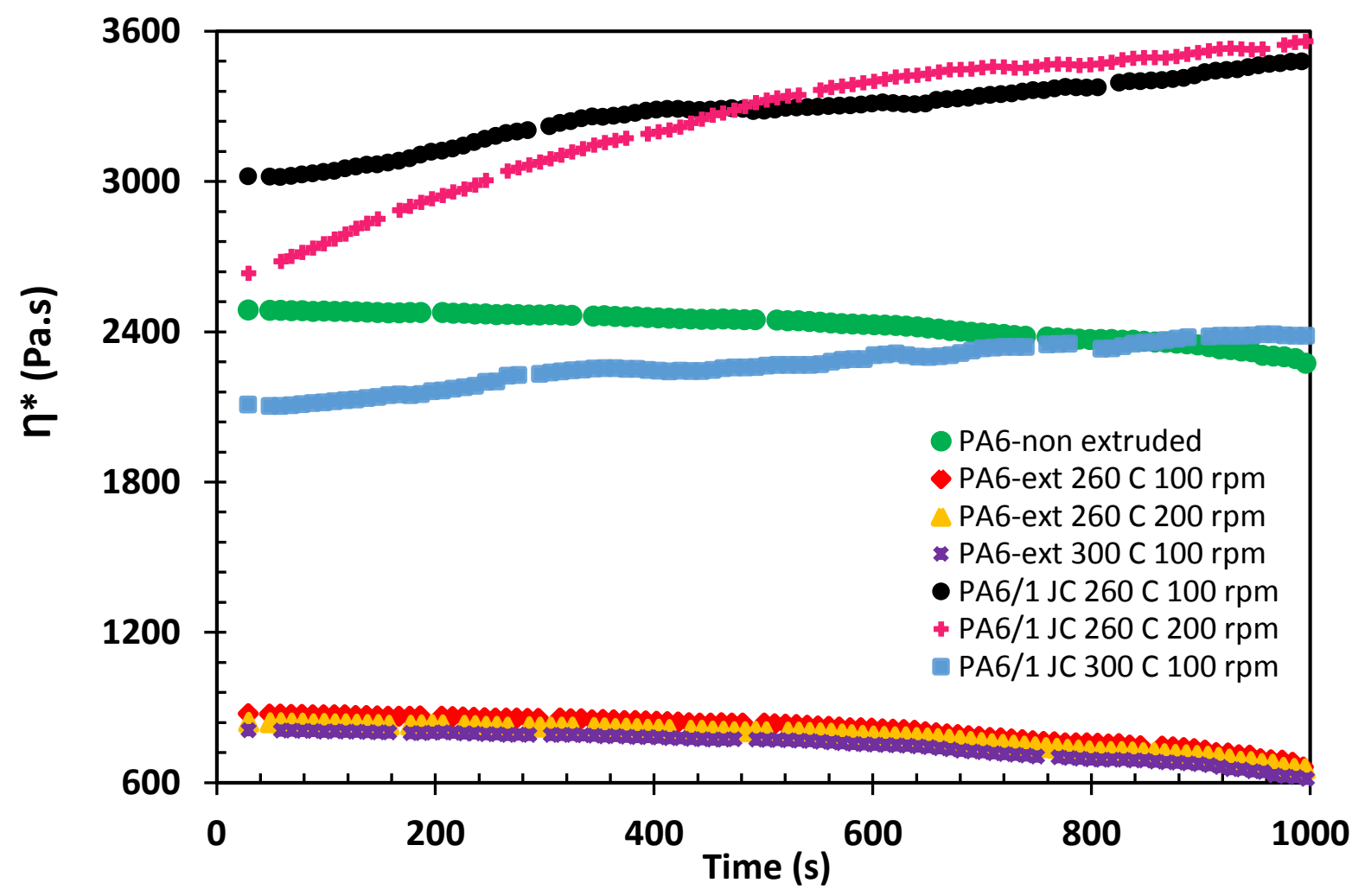

Fig. 2: Complex viscosity $\eta^{*}$ vs. time $1 \mathrm{~Hz}$ of PA6 and PA6-Joncryl

Table 3: Complex viscosity of the samples at 200, 400 and $800 \mathrm{~s} 1 \mathrm{~Hz}$ of PA6 and PA6-Joncryl

\begin{tabular}{cccc}
\hline Sample & $\begin{array}{c}\boldsymbol{\eta}^{*} \text { at 200 s } \\
\text { (Pa.s) }\end{array}$ & $\begin{array}{c}\boldsymbol{\eta}^{*} \text { at 400 s } \\
\text { (Pa.s) }\end{array}$ & $\begin{array}{c}\boldsymbol{\eta}^{*} \text { at 800 s } \\
\text { (Pa.s) }\end{array}$ \\
\hline PA6-non extruded & 2476 & 2455 & 2369 \\
PA6-ext 260 ${ }^{\circ} \mathrm{C} 100 \mathrm{rpm}$ & 865 & 844 & 757 \\
PA6-ext 260 ${ }^{\circ} \mathrm{C} 200 \mathrm{rpm}$ & 831 & 813 & 727 \\
PA6-ext $300{ }^{\circ} \mathrm{C} 100 \mathrm{rpm}$ & 798 & 779 & 692 \\
PA6/1 JC $260^{\circ} \mathrm{C} 100 \mathrm{rpm}$ & 3118 & 3286 & 3375 \\
PA6/1 JC $260^{\circ} \mathrm{C} 200 \mathrm{rpm}$ & 2931 & 3198 & 3465 \\
PA6/1 JC $300^{\circ} \mathrm{C} 100 \mathrm{rpm}$ & 2161 & 2243 & 2331 \\
\hline
\end{tabular}

Fig. 3 displays the data in the form of complex viscosity $\eta^{*}$ changes as the deformation frequency is increased from 0.1 to $100 \mathrm{~Hz}$ at a very small strain, $0.1 \%$. Here we are attempting to preserve the structure in the linear elastic range and assess its strength in an attempt to infer the effect of Joncryl on PA6. Again and as in Fig. 2, the relative change is striking, nearly a four-fold increase at the lowest frequency of $0.1 \mathrm{~Hz}$ when we hardly disturb 
12

the structure. Clearly and as expected, upon increasing the deformation frequency, we are breaking the structure resulting in the observed decrease of complex viscosity $\eta^{*}$. The interesting observation is again the effect of reaction time. When we compare the data at 260 ${ }^{\circ} \mathrm{C}$ and screw speeds of $100 \mathrm{rpm}$ (residence time of $63 \mathrm{~s}$ according to Table 2) and $200 \mathrm{rpm}$ (residence time of $50 \mathrm{~s}$ according to Table 2), we observe the significant difference at $0.1 \mathrm{~Hz}$ in the value $\eta^{*}$ (4000 Pa.s compared to 3000 Pa.s) hence the need for time for Joncryl to complete the chain extension of PA6. This data together with the value of $\eta^{*}$ at $0.1 \mathrm{~Hz}$ for the neat PA6 (1000 Pa.s) provide engineering estimate of the kinetics of the chain extension reaction. By kinetics estimate, it is meant working out on the basis of viscosity changes (Table 3) how the reaction of PA6 with Joncryl proceeds in time and how this time is affected by extrusion screw speed and temperature.

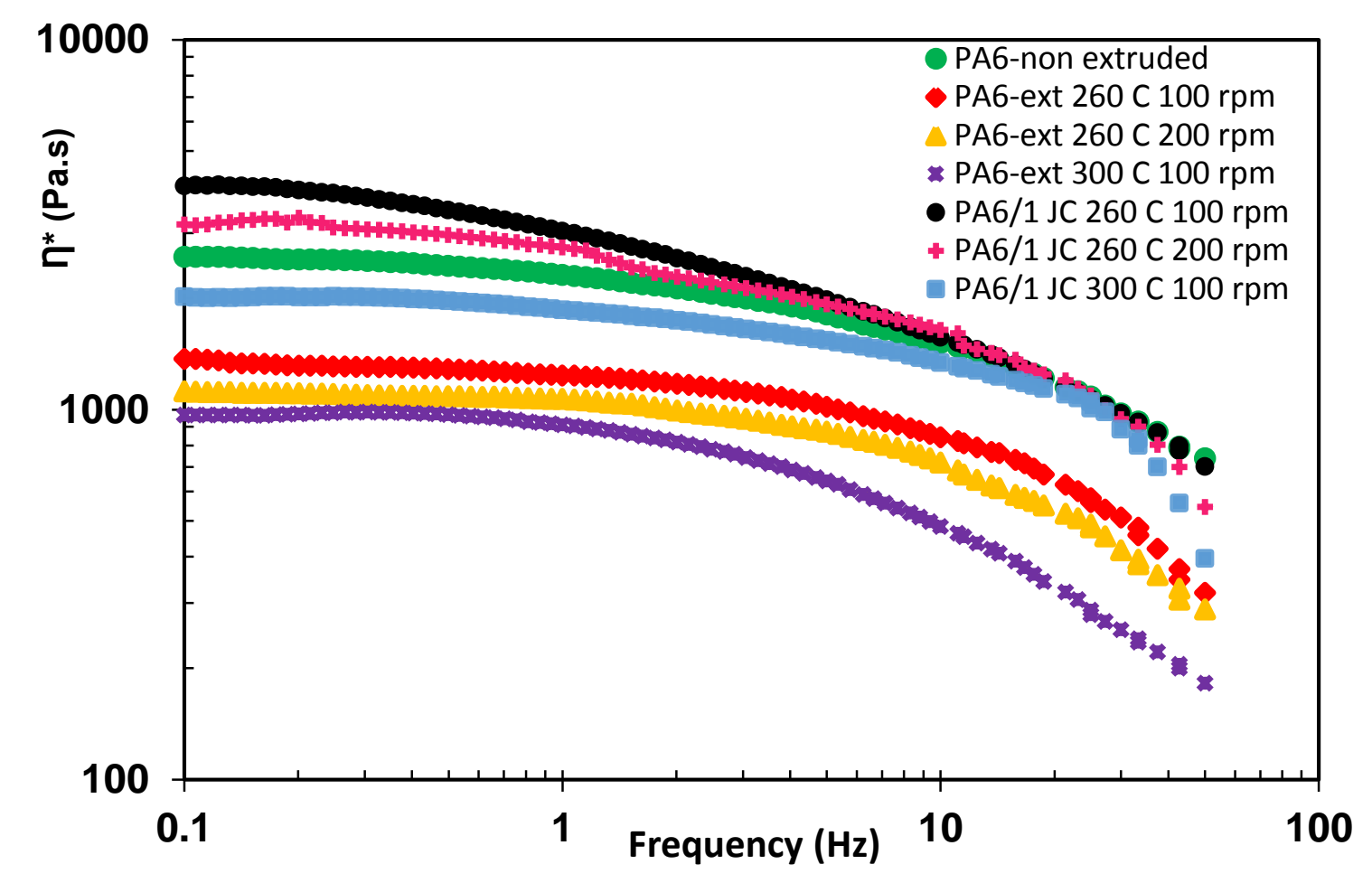

Fig. 3: Complex viscosity $\eta{ }^{*}$ vs. frequency of PA6 and PA6-Joncryl

To complete the rheological case that chain extension of PA6 with Joncryl is very effective, the data are also presented in the guise of the storage modulus $G^{\prime}$ versus deformation frequency in Fig. 4. The pertinent values are again those at the lowest deformation frequency where the structure is at its least disturbed state and revealing the true extent of the chain extension. Again the same observation can be made: a striking relative change between $G^{\prime}$ of neat PA6 and PA6 compounded with Joncryl at $0.1 \mathrm{~Hz}$ : $35 \mathrm{~Pa}$ compared to $450 \mathrm{~Pa}$ for $260^{\circ} \mathrm{C}$ and $100 \mathrm{rpm}, 25 \mathrm{~Pa}$ compared to $270 \mathrm{~Pa}$ for $260{ }^{\circ} \mathrm{C}$ and 200 rpm and $22 \mathrm{~Pa}$ compared to $110 \mathrm{~Pa}$ for $300{ }^{\circ} \mathrm{C}$ and $100 \mathrm{rpm}$.

It is now interesting to assess the data against the rheological principle of timetemperature superposition which states that changes in temperature lead to change in molecular motion rate whilst molecular relaxation remains unchanged [27]. This principle holds only for thermo-rheologically simple material. During chain extension reactions, molecular motion rate and sequence of molecular processes are affected by changes in temperature as a reaction is occurring. Thus, in the reacting case, we can expect the data not to superimpose but to show a shift that is dependent on temperature and frequency. This is 
1 precisely what we observe from the comparative data of Fig. 5: the unreacted PA6 samples 2 give modulus values measured at the 260, 270 and $280{ }^{\circ} \mathrm{C}$ temperatures tested that 3 superimpose whereas the reacted PA6+JC samples show a shift.

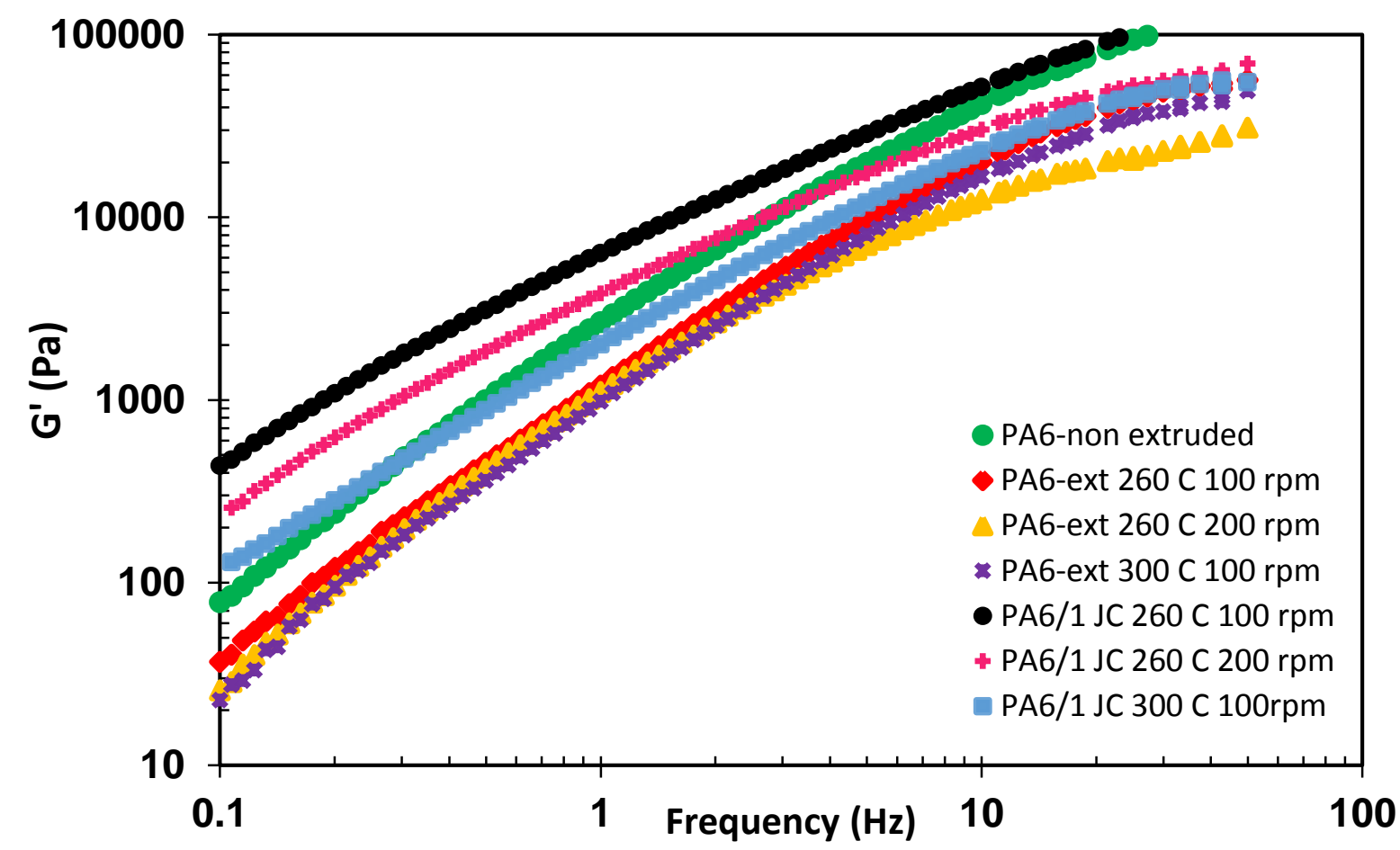

Fig. 4: Storage modulus G' vs. frequency of PA6 and PA6-Joncryl

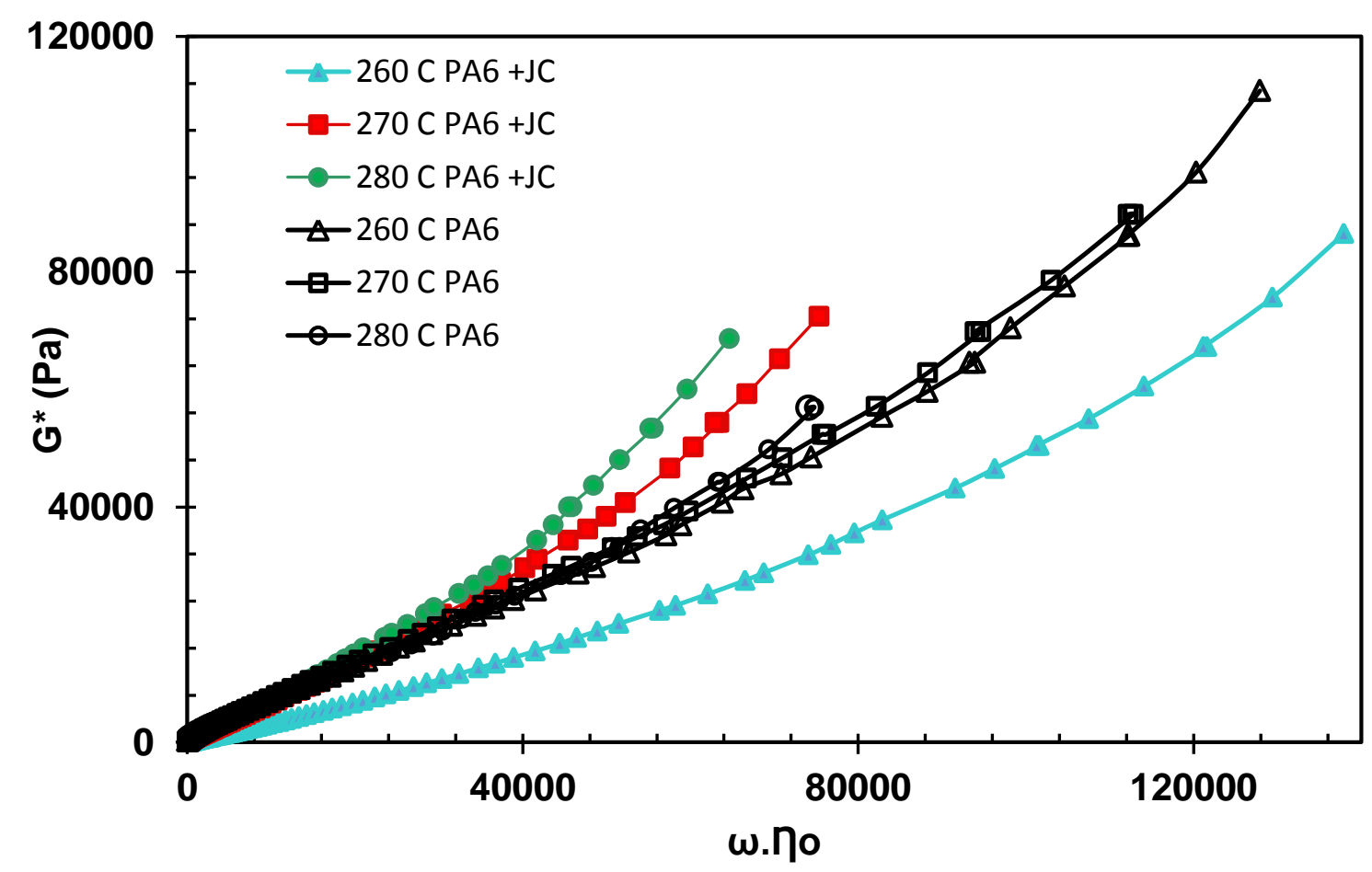

Fig. 5: Time-temperature superposition principle applied to PA6 with Joncryl 
The data so far presented have been at $1 \mathrm{wt}$. \% dosage of Joncryl into PA6, following the manufacturers recommendation. Fig. 6 presents data for the complex viscosity variation with deformation frequency at dosage $50 \%$ higher to assess the criticality of the dosage. On the basis of this data, it is seen that at 1.5 wt. \% dosage the chain extension has reduced compared to $1 \mathrm{wt}$ \% dosage. Data for the storage modulus variation with frequency, not presented here, lead to the same conclusion. The effect of chain extender loading can be explained by considering the reaction mechanism at equilibrium. When an optimum amount of Joncryl is added to PA6, amide end groups of PA6 and anhydride groups of Joncryl react and result in a decrease in active chain end concentration of PA6. On the other hand, in the case of excess amount of Joncryl, Joncryl starts to react with all amide end groups of PA6 and leads to a large displacement away from the equilibrium. In order to put the system back into equilibrium, amide groups must be released by chain scission of PA6, and this will lead to a molecular weight (viscosity) decrease. These results confirmed that the dosage is critical and the recommended limit of $1 \mathrm{wt} . \%$.

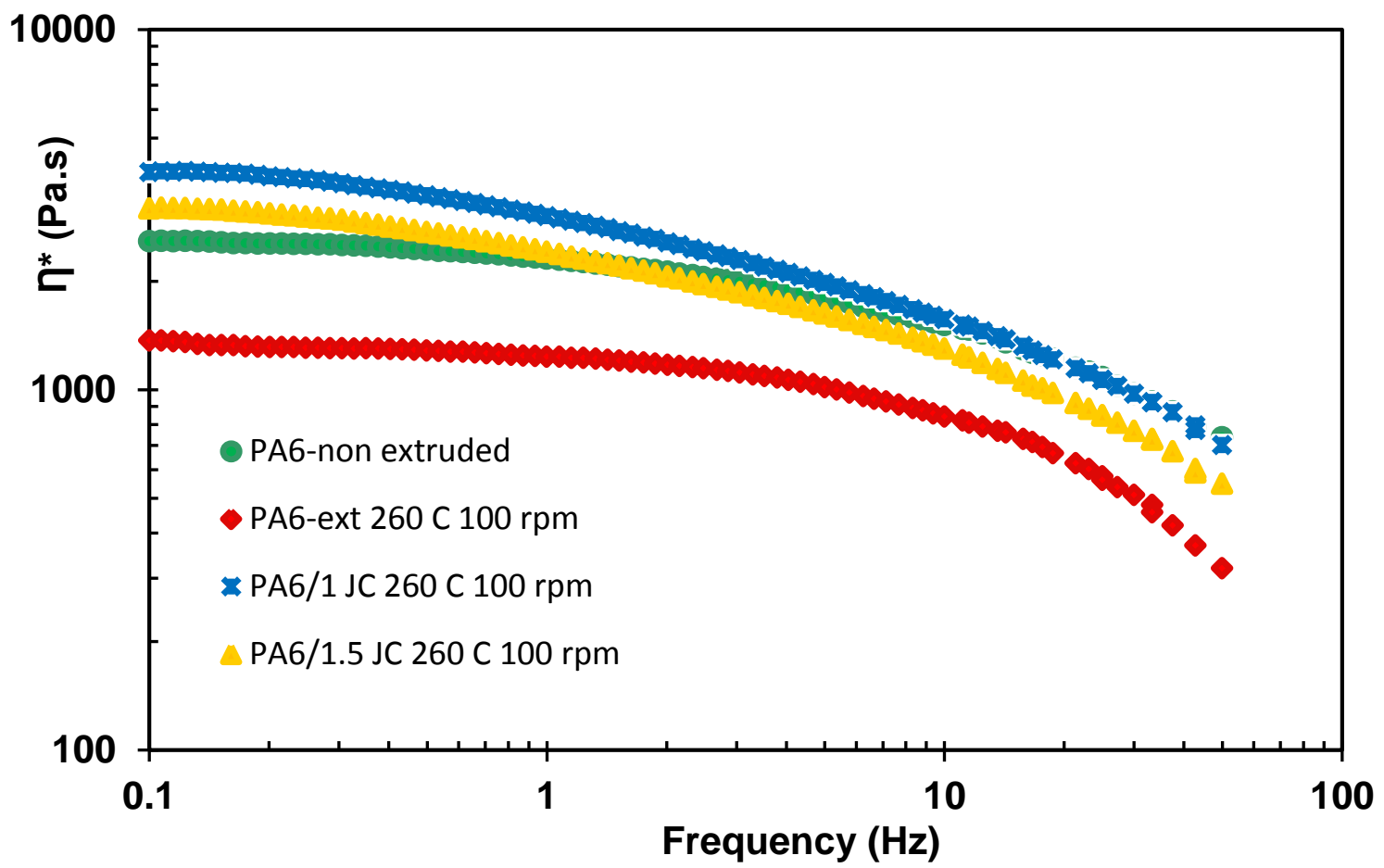

Fig. 6: Complex viscosity $\eta^{*}$ vs. frequency of PA6 and PA6-Joncryl at two JC dosage.

\subsection{Mechanical Properties}

In principle, chain extension should alter mechanical properties in the sense that the otherwise broken molecular structure is reinforced. The extent, in terms of relative changes in the elastic modulus for example, cannot depend solely on this reinforcement but on the way the solid structure develops upon cooling that is the thermal and crystallization properties. Table 4 compares the mechanical properties of the neat PA6 and PA6 compounded with 1 wt. \% Joncryl at $260{ }^{\circ} \mathrm{C}$ and 100 and $200 \mathrm{rpm}$ screw speeds and at $300^{\circ} \mathrm{C}$ and 100rpm screw speed.

In all cases, the increase in the elastic modulus indicate a reinforcement of the structure, here the result of chain extension. The largest change (1686 to $3093 \mathrm{MPa}$ or $85 \%$ increase) occurs at $300{ }^{\circ} \mathrm{C}$ and $100 \mathrm{rpm}$ extrusion conditions, not $260{ }^{\circ} \mathrm{C}$ and $100 \mathrm{rpm}$ as the rheological data above indicated. An explanation for this discrepancy may be attributed to 
how the chain extension effect are presumed to be measured. With rheology, the structure is in the melt phase and the storage modulus for example is measured at low strain with preferably low deformation frequency so as to maintain the deformation in the elastic region. The modulus so measured here will be very sensitive to chain extension thus in essence a better representation of chain extension. With mechanical properties, the melt has been cooled, reheated to form a dumbbell and then stretched in the solid phase. Considerations other than chain extension must play a part, thermal properties and crystallisation, so that interpreting $300{ }^{\circ} \mathrm{C}$ as being the optimum chain extension reaction temperature will be incorrect, albeit that it is the temperature that produces a chain extended PA6 with the highest elastic modulus.

Table 4: Mechanical properties of PA6 with and without Joncryl

\begin{tabular}{lcccc}
\hline \multicolumn{1}{c}{ Sample } & $\begin{array}{c}\text { Tensile modulus } \\
(\mathrm{MPa})\end{array}$ & $\begin{array}{c}\text { Yield } \\
\text { strength } \\
(\mathrm{MPa})\end{array}$ & $\begin{array}{c}\text { Ultimate } \\
\text { tensile strength } \\
(\mathrm{MPa})\end{array}$ & $\begin{array}{c}\text { Yield } \\
\text { strain } \\
(\%)\end{array}$ \\
\hline PA6-non extruded & $2792.42 \pm 39.87$ & $74.65 \pm 2.96$ & $80.70 \pm 1.81$ & $3.34 \pm 0.29$ \\
PA6-ext $260{ }^{\circ} \mathrm{C} 100 \mathrm{rpm}$ & $2198.72 \pm 67.04$ & $60.70 \pm 0.44$ & $72.79 \pm 1.62$ & $3.36 \pm 0.40$ \\
PA6-ext $260{ }^{\circ} \mathrm{C} 200 \mathrm{rpm}$ & $2163.24 \pm 93.99$ & $60.39 \pm 1.76$ & $76.73 \pm 1.91$ & $3.43 \pm 0.15$ \\
PA6-ext $300^{\circ} \mathrm{C} 100 \mathrm{rpm}$ & $1685.78 \pm 68.27$ & $42.54 \pm 0.43$ & $65.93 \pm 0.38$ & $3.69 \pm 0.34$ \\
PA6/1 JC $260^{\circ} \mathrm{C} 100 \mathrm{rpm}$ & $2969.24 \pm 65.57$ & $72.37 \pm 2.45$ & $82.86 \pm 0.34$ & $2.87 \pm 0.15$ \\
PA6/1 JC $260^{\circ} \mathrm{C} 200 \mathrm{rpm}$ & $2901.2 \pm 97.30$ & $65.93 \pm 0.81$ & $82.17 \pm 1.42$ & $2.70 \pm 0.18$ \\
PA6/1 JC $300^{\circ} \mathrm{C} 100 \mathrm{rpm}$ & $3092.8 \pm 11.09$ & $73.79 \pm 0.87$ & $82.31 \pm 0.8$ & $2.75 \pm 0.14$ \\
\hline
\end{tabular}

Yield strength and ultimate tensile strength present additional mechanical properties, supporting structure reinforcement and occurrence of chain extension but not distinguishing uniquely the optimum extrusion parameters controller chain extension. For example; Table 4 presents measured yield strength showing again $300{ }^{\circ} \mathrm{C}$ and $100 \mathrm{rpm}$ as being the extrusion conditions producing the most reinforced compound. We observe however on the basis of this property that extrusion at $260{ }^{\circ} \mathrm{C}$ and $100 \mathrm{rpm}$ produces a compound of almost exactly yield strength. The same is observed when we consider the ultimate tensile strength data. Interestingly and to stress the point further regarding the adequacy of mechanical properties in helping determine optimum chain extension conditions, yield strain data are presented in Table 4. With yield strain values of $2.75 \%$ and $2.87 \%$, we cannot conclude on whether 260 ${ }^{\circ} \mathrm{C}$ or $300{ }^{\circ} \mathrm{C}$ is the optimum temperature. What is measurable are the larger yield strains without addition of Joncryl, 3.69\% and 3.36\%, confirming the extension reinforcing action of Joncryl.

\subsection{Thermal Properties}

Here the DSC data obtained are used to assess the occurrence and extent of chain extension when Joncryl is added. In principle [28], extended chain in a polymer occupy a larger free volume and this should be reflected in an increased glass transition temperature. Table 5 shows that this the case, albeit that the increase is relatively small, from 52 to $55^{\circ} \mathrm{C}$ and does not differentiate the effect of temperature and screw speed. 
With regard to crystallization, we observe from Table 5 that unlike the neat PA6, the samples compounded with Joncryl exhibit two melting points, a proof that a change has occurred to the crystal phase, possibly the formation of a $\gamma$ crystalline phase $[29,30]$ here at $209{ }^{\circ} \mathrm{C}$. Also, the DSC data as shown in Table 5 reveal that the incorporation of Joncryl decreased the crystallinity of PA6 but only marginally. Similar observations were made by Lu et al. [23] who used bisoxazolines and Buccella et al. [25] who used CBC chain extenders. A plausible explanation for this increase is that the extended chains hinder arrangement in crystal structure. It must be noted that other studies by Loontjens [16] and Ghanbari et al. [31] reported no changes in the degree in crystallinity. It may be thus that the changes we measured being small may be due to experimental errors. The important observation is that with the addition of Joncryl there is a change in the melting peak suggesting a structural change has occurred.

14

Table 5: Thermal properties of PA6 with and without Joncryl

\begin{tabular}{lccccc}
\hline Sample & $\mathbf{T}_{\mathrm{g}}\left({ }^{\circ} \mathrm{C}\right)$ & $\mathbf{T}_{\mathrm{m}}\left({ }^{\circ} \mathrm{C}\right)$ & $\mathbf{T}_{\mathrm{c}}\left({ }^{\circ} \mathrm{C}\right)$ & $\mathbf{X}_{\mathrm{c}}(\%)$ & $\mathbf{T}_{\text {onset }}\left({ }^{\circ} \mathrm{C}\right)$ \\
\hline PA6-non extruded & 53.7 & 221.1 & 188.4 & 20.2 & 416.6 \\
PA6-ext $260{ }^{\circ} \mathrm{C} 100 \mathrm{rpm}$ & 51.8 & 221.5 & 187.9 & 19.7 & 395.9 \\
PA6-ext $260{ }^{\circ} \mathrm{C} 200 \mathrm{rpm}$ & 51.8 & 221.3 & 188.4 & 20.5 & 389.2 \\
PA6-ext $300{ }^{\circ} \mathrm{C} 100 \mathrm{rpm}$ & 51.6 & 221.3 & 187.9 & 20.2 & 378.5 \\
PA6/1 JC $260{ }^{\circ} \mathrm{C} 100 \mathrm{rpm}$ & 55.5 & $209.1 / 222.6$ & 187.7 & 18.6 & 396.1 \\
PA6/1 JC $260{ }^{\circ} \mathrm{C} 200 \mathrm{rpm}$ & 54.4 & $209.2 / 221.2$ & 187.4 & 19.0 & 390.3 \\
PA6/1 JC $300{ }^{\circ} \mathrm{C} 100 \mathrm{rpm}$ & 55.0 & $209.4 / 223.0$ & 186.5 & 17.8 & 386.1 \\
\hline
\end{tabular}

TGA curves of PA6 with and without chain extender extruded at $300{ }^{\circ} \mathrm{C}$ are shown in Fig. 7. The region of interest is pre-complete degradation during the TGA measurements that is up to $300{ }^{\circ} \mathrm{C}$. The data shows that (i) the PA6-non extruded is the least degrading, (ii) PA6 extruded at $300^{\circ} \mathrm{C} 100 \mathrm{rpm}$ the most rapidly degrading and (iii) PA6-Joncryl extruded at 300 ${ }^{\circ} \mathrm{C} 100 \mathrm{rpm}$ sit between these two extremes. This is proof that the addition of Joncryl rebuilds molecular weight and delays degradation to higher temperatures as observed in the rest of the curves at temperature higher than $300{ }^{\circ} \mathrm{C}$ (not presented here).

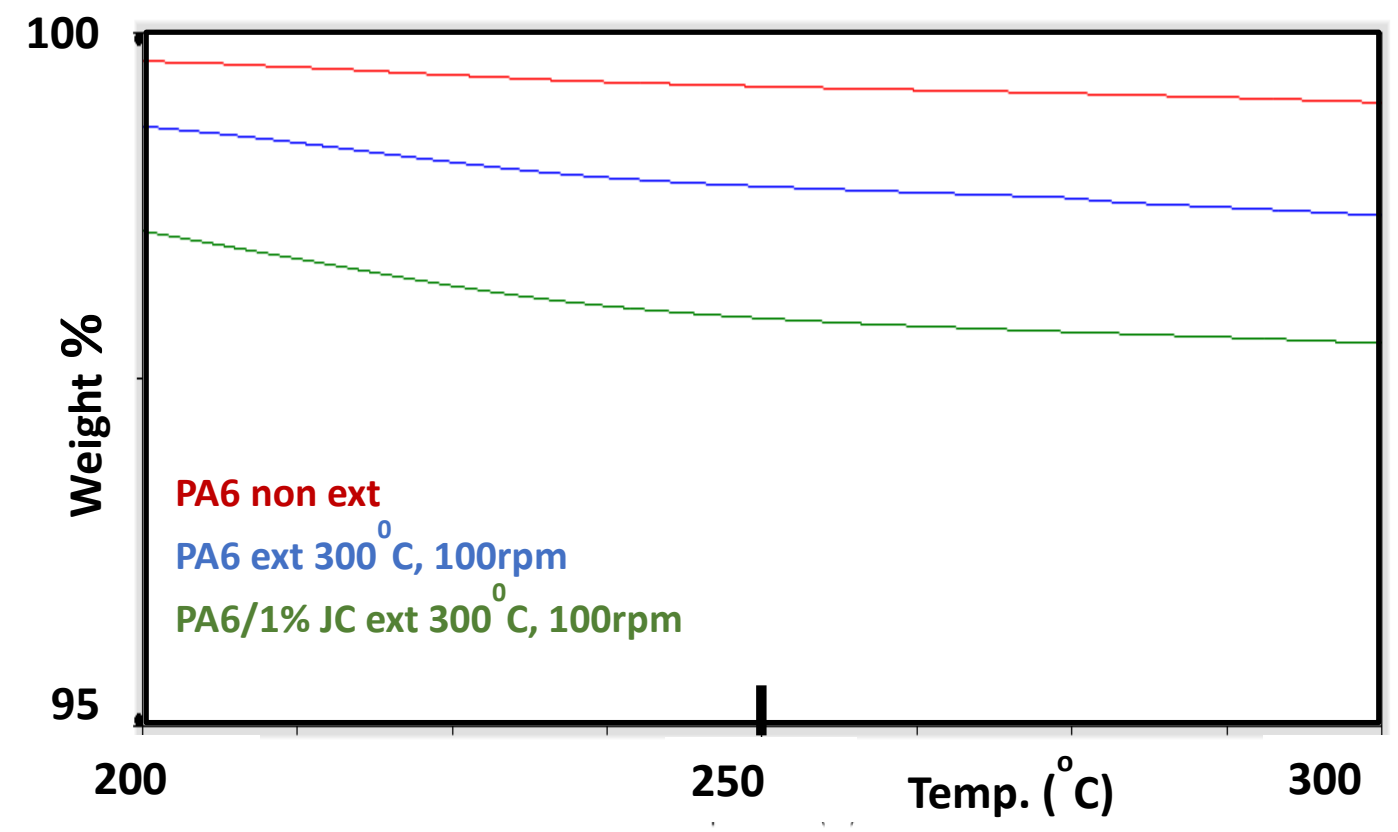


Fig.7: TGA comparison of non-extruded PA6 with PA6 and PA6-1wt\% Joncryl extruded at $300{ }^{\circ} \mathrm{C} 100 \mathrm{rpm}$ at TGA temperature below $300{ }^{\circ} \mathrm{C}$

\section{CONCLUSIONS}

Extrusion induced degradation of PA6 is commonly known and was observed clearly in this study from rheological, tensile test and thermo-gravimetric measurements. PA6 extruded at temperature of $300{ }^{\circ} \mathrm{C}$ showed a $40 \%$ decrease in tensile modulus compared to non-extruded PA6. A review of previous work on chain extension of PA6 led us to the hypothesis that multi-anhydride functionalities would be best suited to chain extend degrading PA6 and this has led us to trialling this novel Joncryl ${ }^{\circledR}$ ADR 3400, a styrene maleic anhydride copolymer with multiple anhydride groups. As explained in Fig.1, with thermal only degradation it is the amide $\mathrm{CONH}_{2}$ groups that must be the reconnecting links. A mechanism for chain extension is thus that which results from the reaction of the amide end group of PA6 with the anhydride group of maleic anhydride as shown in Fig. 8.

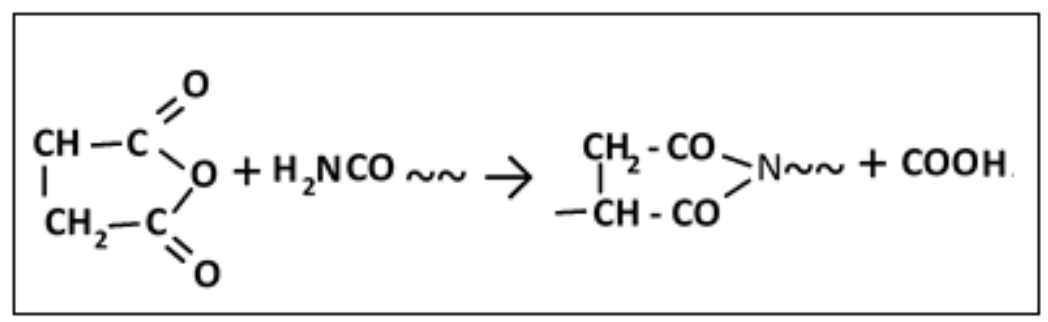

Fig. 8: Reaction between PA6 amide end group and anhydride group.

Viscoelastic data most conclusively support the hypothesis. A striking relative change was measured between $\mathrm{G}^{\prime}$ of neat PA6 and PA6 compounded with Joncryl: 35 Pa compared to $450 \mathrm{~Pa}$ for $260{ }^{\circ} \mathrm{C}$ and $100 \mathrm{rpm}, 25 \mathrm{~Pa}$ compared to $270 \mathrm{~Pa}$ for $260{ }^{\circ} \mathrm{C}$ and $200 \mathrm{rpm}$ and 22 Pa compared to $110 \mathrm{~Pa}$ for $300{ }^{\circ} \mathrm{C}$ and $100 \mathrm{rpm}$. This data is further supported by tensile test measurements which showed increases of as much as $85 \%$ in the elastic modulus of PA6 compounded with 1 wt. \% Joncryl. Thermal data such as those from DSC reveals a clear change in the thermal peak but with little if any changes in crystallinity between PA6 and PA6 extruded with Joncryl. Finally, TGA data, when analysed in the region of interest that is close to $300{ }^{\circ} \mathrm{C}$ where degradation is deemed to begin, also showed that (i) the neat PA6 is the least degrading, (ii) PA6 extruded at $300{ }^{\circ} \mathrm{C}$ the most rapidly degrading and (iii) PA6Joncryl extruded at $300{ }^{\circ} \mathrm{C}$ sit between these two extremes. These observations (the rheology and mechanical properties data in particular) provide conclusive proof that the addition of Joncryl rebuilds molecular weight and delays degradation to higher temperatures.

\section{ACKNOWLEDGEMENTS}

Dr B. Tuna acknowledges the financial support of the Republic of Turkey, Ministry of National Education and the support of Dr A. Kelly in his role as Associate Supervisor during 
1 her PhD study at the University of Bradford. The authors thank BASF, Germany for

2 supplying Joncryl ${ }^{\circledR}$ ADR 3400.

3

4 7. REFERENCES

5 1. W.H. Carothers, J. Am. Chem. Soc., 51 (1929).

6 2. F. Faridirad, S. Ahmadi, and M. Barmer, Polym. Eng. Sci., 57 (2017).

7 3. M. Yuan, L-S. Turng, S. Gong, D. Caulfield, C. Hunt, and R. Spindler, Polym. Eng. Sci., $8 \quad 44,4(2004)$.

9 4. F. Gao, Mater. Today, 7, 11 (2004).

10 5. J.E. Crespo, F. Parres, M.A. Peydro, and R. Navarro, Polym. Eng. Sci., 53, 4 (2013).

11 6. S.V. Levchik, E.D. Weil, and M. Lewin, Polym. Int., 48, 7 (1999).

12

7. H.J. Dussel, H. Rosen, and D.O. Hummel, Macromol. Chem. Phys., 177, 8 (1976).

8. B. Tuna, and H. Benkreira, Polym. Eng. Sci., (2017) doi:10.1002/pen.24663.

9. L. Xia, B. Shentu, and Z. Wang, Polym. Eng. Sci., 54 (2014).

10. P.J. Flory, U.S. Patent, 2173373 (1939).

11. H. Li, and M.A. Huneault, J. Appl. Polym. Sci., 122, 1 (2011).

12. N. Najafi, M.C. Heuzey, P.J. Carreau, and P.M. Adams, Polym. Degrad. Stab., 97, 4 (2012).

13. L. Xiao, H. Wang, Q. Qian, X. Jiang, X. Liu, B. Huang, and Q. Chen, Polym. Eng. Sci., 52, $10(2012)$.

14. Q. Meng, M.C. Heuzey, and P.J. Carreau, Polym. Degrad. Stab., 97, 10 (2012).

15. H. Eslami, and R.M. Kamal, J. Appl. Polym. Sci., 129, 5 (2013).

16. A. Ghanbari, M.C. Heuzey, P.J. Carreau, and M.T. Ton-That, Polymer, 54 (2013).

17. R. Al-Itry, K.S. Lamnawar, and A. Maazouz, Eur. Polym. J., 58 (2014).

18. F. Carrasco, J. Cailloux, P.E. Sánchez-Jiménez, and M.L. Maspoch, Polym. Degrad. Stab., 104 (2014).

19. F. Awaja, F. Daver, and E. Kosior, Polym. Eng. Sci., 44, 8 (2004).

20. M. Mihai, M.A. Huneault, and B.D. Favis, Polym. Eng. Sci., 50, 3 (2010). 
1 21. F.N. Cavalcanti, E.T. Teofilo, M.S. Rabello, and S.M.L. Silva, Polym. Eng. Sci., 47, 12 2 (2007).

3 22. T. Loontjens, K. Pauwels, F. Derks, M. Neilen, C.K. Sham, and M. Serné, J. Appl. 4 Polym. Sci., 65, 9 (1997).

5 23. C. Lu, T. Chen, X. Zhao, X. Ren, and X. Cai, J. Polym. Sci. B Polym. Phys., 45, 15 6 (2007).

7 24. J.A. Loontjens, and B.J.M. Plum, U.S. Patent, 6228980B1 (2001).

8 25. M. Buccella, A. Dorigato, E. Pasqualini, M. Caldara, and L. Fambri, Polym. Eng. Sci., $9 \quad \mathbf{5 4 , 1}(2014)$.

10 26. BASF, Technical Data Sheet Joncryl ${ }^{\circledR} A D R$ 3400, (2012).

11 27. J.M. Dealy, and K.F. Wissbrun, Melt Rheology and Its Role in Plastics Processing:

12 Theory and Applications, Dordrecht: Kluwer Academic Publishers (1999).

13 28. T.G. Fox, and P.J. Flory, J. Appl. Phys., 21, (1950).

14 29. T.D. Fornes, and D.R. Paul, Polymer, 44, 14 (2003).

15 30. S. Xie, S. Zhang, H. Liu, G. Chen, M. Feng, H. Qin, F. Wang, and F. Yang, Polymer, 46, $1614(2005)$.

17 31. J.A. Loontjens, Performance materials by a modular approach, Ph.D. Thesis, Eindhoven 18 University of Technology, (2005). 